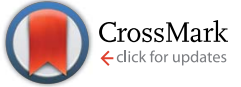

Cite this: RSC Adv., 2017, 7, 3161

Received 10th November 2016 Accepted 17th December 2016

DOI: 10.1039/c6ra26591j

www.rsc.org/advances

\section{Environmentally friendly and facile synthesis of Rh nanoparticles at room temperature by alkaline ethanol solution and their application for ethanol electrooxidation $\uparrow$}

\begin{abstract}
Fuhai Li, ${ }^{a}$ Hanqin Weng, ${ }^{a}$ Yun Shang, ${ }^{a}$ Zuoming Ding, ${ }^{a}$ Zheng Yang, ${ }^{a}$ Sheng Cheng ${ }^{b}$ and Mingzhang Lin*ac

Rhodium (Rh) is one of the most important catalyst constituents in many industrial catalytic processes. The synthesis of rhodium nanoparticles (RhNps) has received considerable interest for decades. In this paper, we report an environmentally friendly and facile synthesis route of $\mathrm{RhNps}$ through direct reduction of $\mathrm{RhCl}_{3}$ by ethanol in an alkaline medium in the presence of PVP at room temperature, confirmed by UV-vis spectroscopy, TEM, XRD and XPS. The effects of the concentrations of $\mathrm{OH}^{-}$and ethanol, as well as the nature of the alcohols, which greatly affected the formation rate of RhNps, were systematically investigated to understand the mechanism. Our results support that ethoxy anions generated from the deprotonation of ethanol were highly active and responsible for the formation of RhNps. Electrochemical tests have shown that $\mathrm{Rh} / \mathrm{C}$ displayed zero activity in an acid medium, while in an alkaline medium $\mathrm{Rh} / \mathrm{C}$ was highly active and displayed enhanced catalytic activity towards ethanol oxidation compared to commercial Rh/C. The process presented in this work is expected to be useful for preparing Rh-based nanocatalysts at room temperature, which may be extended to other nanocatalysts.
\end{abstract}

\section{Introduction}

Noble-metal nanoparticles have received considerable attention over the past decades due to their remarkable properties and potential applications in photonics, electronics, sensing, biomedical research and catalysis, which are significantly different from their bulk form. ${ }^{1-6}$ It has been reported that rhodium nanoparticles (RhNps) can be used as catalysts in so many reactions such as the oxidation of carbon monoxide, hydrocarbonylation, hydroformylation, hydrogenation, methanation of carbon dioxide and Fischer-Tropsch reactions. ${ }^{7-11}$ Especially, noble-metal nanoparticles have been extensively employed as electrocatalysts for direct fuel cell applications. Compared to the acidic-electrolyte direct ethanol fuel cell (DEFC), direct alkaline ethanol fuel cells (DAEFCs) possess several advantages: faster reaction kinetics, higher energy densities, easy handling of the liquid fuels and no need for fluorinated polymers. ${ }^{12-15}$ Great efforts have been devoted to the

${ }^{a}$ School of Nuclear Science and Technology, University of Science and Technology of China, Hefei 230026, P. R. China. E-mail: gelin@ustc.edu.cn

${ }^{b}$ Instrumental Analysis Center, Hefei University of Technology, Hefei 230009, P. R. China

'Institute of Nuclear Energy Safety Technology, Chinese Academy of Sciences, Hefei 230031, P. R. China

$\dagger$ Electronic supplementary information (ESI) available. See DOI: 10.1039/c6ra26591j study of DAEFCs especially the development of electrode catalyst materials. However, it remains particularly difficult to break the $\mathrm{C}-\mathrm{C}$ bond in alcohols except methanol during electrochemical oxidation. ${ }^{\mathbf{1 6 - 1 8}}$ Therefore the research and development of catalyst materials highly active towards the break of $\mathrm{C}-\mathrm{C}$ bond plays a pivotal role. Recently several works reported the enhancement of complete electrooxidation of ethanol to $\mathrm{CO}_{2}$ by the addition of $\mathrm{Rh}$ to Pt catalysts in acid medium, without a significant enhancement of the overall kinetics. ${ }^{19-24}$ Kowal et $a l^{25}$ and $\mathrm{Li}$ et $a .^{23}$ obtained remarkable ethanol oxidizing efficiency employing $\mathrm{PtRhSnO}_{2} / \mathrm{C}$ as electrocatalyst. $\mathrm{Rh}$ was found to play a significant role in facilitating $\mathrm{C}-\mathrm{C}$ bond cleavage. Rh alone was also found to be quite active towards ethanol electrooxidation in alkaline medium, ${ }^{26,27}$ while in acid medium it is practically inactive. ${ }^{23,25}$ Suo et al. ${ }^{26}$ found $\mathrm{Rh} / \mathrm{C}$ showed a higher activity for ethanol oxidation at low potentials than $\mathrm{PdRh} / \mathrm{C}$ and $\mathrm{Pd} / \mathrm{C}$ in alkaline medium. Fontes et al. ${ }^{27}$ observed a remarkable good activity of $\mathrm{Rh} / \mathrm{C}$ for ethanol oxidation in the first minutes. These results demonstrated that Rhbased catalysts are promising catalyst candidates for complete ethanol oxidation with excellent properties at low potentials in alkaline medium.

A variety of methods have been employed in the production of RhNps since Toshima et al. ${ }^{28}$ first reported the synthesis of RhNps in 1978 in methanol-water solution in the presence of poly(vinyl alcohol) (PVA) at $79^{\circ} \mathrm{C}$. The polyol methods ${ }^{29-33}$ have 
been most widely employed in the preparation of RhNps, which require harsh reducing conditions, typically consist in refluxing a mixture of a precursor salt (e.g., $\mathrm{RhCl}_{3}$ or $\mathrm{Na}_{3} \mathrm{RhCl}_{6}$ ), a polyalcohol (e.g., ethylene glycol) and a stabilizing agent [e.g., poly(vinyl pyrrolidone) (PVP) or PVA] at high temperatures (60-190 ${ }^{\circ} \mathrm{C}$ ) for $1-24 \mathrm{~h}$, which is tedious and not-easy-operating, energy and time consuming. A photochemical approach ${ }^{34}$ has also been reported for the generation of shape selective RhNps. The photochemical approach brings the inconvenience of demanding continuous irradiation from a light source for $6 \mathrm{~h}$, although it was conducted at room temperature. RhNps have been produced based on the chemical reduction methods using borohydride as a reducing agent. ${ }^{35,36}$ However, borohydride should be carefully treated since it is toxic to health and unstable.

In this work, we report for the first time a facile and environmentally friendly synthesis route of RhNps through direct reduction of $\mathrm{RhCl}_{3}$ by ethanol in alkaline medium in the presence of PVP under aerobic conditions at room temperature $\left(20{ }^{\circ} \mathrm{C}\right)$. Compared with other room temperature reducing agents such as $\mathrm{BH}_{4}{ }^{-}$, ethanol is more eco-friendly due to its biomass origin and easy biodegradation. The reaction mechanism was discussed by studying the effects of various parameters such as the concentrations of $\mathrm{OH}^{-}$and ethanol, as well as the nature of alcohols, which greatly affect the formation rate of RhNps. Moreover, the electrocatalytic activities of carbonsupported RhNps in both acid and alkaline medium were also studied.

\section{Experimental}

\section{Chemicals}

Rhodium chloride hydrate $\left(\mathrm{RhCl}_{3} \cdot x \mathrm{H}_{2} \mathrm{O}, 99.98 \%\right)$ was purchased from Sigma-Aldrich Co., Ltd. Poly(vinylpyrrolidone) (PVP, K-30), sodium hydroxide ( $\mathrm{NaOH}, 96 \%)$, methanol $\left(\mathrm{CH}_{3} \mathrm{OH}\right.$, $99.7 \%)$, ethanol $\left(\mathrm{C}_{2} \mathrm{H}_{5} \mathrm{OH}, 99.7 \%\right)$, isopropanol $\left(\left(\mathrm{CH}_{3}\right)_{2} \mathrm{CHOH}\right.$, 99.7\%) and tert-butyl alcohol $\left(\left(\mathrm{CH}_{3}\right)_{3} \mathrm{COH}, 99.7 \%\right)$ were obtained from Sinopharm Chemical Reagent Co., Ltd. Commercial Rh/C (5 wt\%) was purchased from Aladdin Co., Ltd. All the above chemicals were of analytical grade and used without further purification. Vulcan XC-72 carbon was purchased from E-TEK Co., Ltd. Nafion solution (5\%) was purchased from Dupont Co., Ltd. Ultrapure water (18.25 $\mathrm{M} \Omega \mathrm{cm})$, generated by a Kertone Lab VIP®, was used in all experiments.

\section{Synthesis of colloidal and carbon-supported RhNps}

In a typical synthesis of colloidal RhNps, PVP (0.229 g) was dissolved in water $(22.5 \mathrm{~mL})$. Then $\mathrm{RhCl}_{3}$ aqueous solution (2.5 $\mathrm{mL}, 20 \mathrm{mM}$ ) was pipetted into the above solution. In a separate flask, determined quantities of ethanol and $\mathrm{NaOH}$ were dissolved in water $(22.5 \mathrm{~mL})$. The ethanol-NaOH solution was then poured into the $\mathrm{RhCl}_{3}-\mathrm{PVP}$ solution under stirring to yield a mixture. The ethanol concentration was varied from $0.1 \mathrm{M}$ to $2.0 \mathrm{M}$. The $\mathrm{NaOH}$ concentration was varied from $0.2 \mathrm{M}$ to $1.0 \mathrm{M}$. The reddish $\mathrm{RhCl}_{3}-\mathrm{PVP}$ solution finally turned into a dark brown solution after consecutive color changes. Then the
RhNps were collected by centrifugation $(10000 \mathrm{rpm}, F=9280 \times$ $g, 20 \mathrm{~min}$ ) and washed with water three times to remove $\mathrm{NaOH}$ and excess PVP.

Carbon-supported RhNps were prepared through the same process, but in which XC-72 carbon was first dispersed in water $(22.5 \mathrm{~mL})$ under ultrasonification instead of PVP. In this way the RhNps were produced directly onto Vulcan carbon without stabilization by PVP. The final concentrations were $1 \mathrm{mM} \mathrm{Rh}$ (III), $1 \mathrm{M}$ ethanol, $1 \mathrm{M} \mathrm{NaOH}$. Finally the product was filtered, washed with water and dried at $65{ }^{\circ} \mathrm{C}$ for $12 \mathrm{~h}$.

\section{Characterizations}

The UV-visible (UV-vis) spectra were recorded in a spectrophotometer (UV-2600, Shimadzu). The absorbance variation at a specific wavelength as a function of time was recorded by fixing the wavelength and measuring the absorbance variations every $10 \mathrm{~s}$ immediately after mixing the reactants directly in the UV cuvette. The morphology of the synthesized RhNps was examined with high resolution transmission electron microscopy (HR-TEM) (JEOL 2010) at $200 \mathrm{kV}$. The energy dispersive Xray spectrum (EDX) was recorded with an INCA energy system (Oxford Instruments) connected with the TEM. The samples were prepared by pipetting RhNps colloidal suspensions onto carbon coated $\mathrm{Cu}$ grids and then dried at room temperature. The metallic loading of $\mathrm{Rh} / \mathrm{C}$ was measured by ICP-MS (X Series 2, Thermo Fisher Scientific). The powder X-ray diffraction (XRD) patterns of the samples were collected on a powder diffraction system (TTR-III, Rigaku) using a $\mathrm{Cu} \mathrm{K} \alpha$ radiation source $(\lambda=$ $1.54178 \AA$ ) operating at $40 \mathrm{kV}$ and $200 \mathrm{~mA}$. The composition and valence state of the synthesized nanoparticles were identified by $\mathrm{X}$-ray photoelectron spectroscopy (XPS) analysis (ESCALAB 250, Thermo-VG Scientific) with monochromatic Al K $\alpha$ irradiation $(h \nu=1486.6 \mathrm{eV})$. Energy normalization was accomplished by placing the major $\mathrm{C} 1 \mathrm{~s}$ peak at $284.6 \mathrm{eV}$.

\section{Electrocatalytic performance of $\mathrm{Rh} / \mathrm{C}$ toward ethanol oxidation}

Cyclic voltammetry (CV) and amperometric $I-t$ measurements were conducted using a CHI 660E potentiostat (Shanghai Chenhua Device Company, P. R. China) in a three-electrode cell with a glassy-carbon (GC) electrode (working electrode), a platinum foil (counter electrode) and a saturated $\mathrm{Ag} / \mathrm{AgCl}$ electrode (reference electrode). The glassy carbon substrate was polished using alumina slurry $(0.05 \mu \mathrm{m})$ prior to use. To prepare the working electrode, $\mathrm{Rh} / \mathrm{C}(2 \mathrm{mg})$ was dispersed ultrasonically in ethanol $(1 \mathrm{~mL})$ containing Nafion $(5 \%, 10 \mu \mathrm{L})$. The suspension $(10 \mu \mathrm{L})$ was deposited onto the GC electrode $(d=5 \mathrm{~mm})$. The solvent was then evaporated at room temperature. The electrolyte was deaerated by bubbling $\mathrm{N}_{2}$ for $30 \mathrm{~min}$ prior to each experiment. A flow of $\mathrm{N}_{2}$ was maintained over the electrolyte during the measurements. At least 10 cycles were performed before collecting the $\mathrm{CV}$ data with a scan rate of $10 \mathrm{mV} \mathrm{s}^{-1}$ or $50 \mathrm{mV} \mathrm{s}^{-1}$. All the currents are normalized by the surface area of the glassy carbon substrate $\left(0.196 \mathrm{~cm}^{2}\right)$ and are given in unit of $\mathrm{mA} \mathrm{cm}^{-2}$. 


\section{Results and discussion}

\section{Synthesis and characterization of RhNps}

Rhodium(III) chloride exists in the form of a variety of chloroaquorhodium(III) complexes $\left(\left[\mathrm{RhCl}_{6-n}\left(\mathrm{H}_{2} \mathrm{O}\right)_{n}\right]^{(n-3)+}\right)$ when dissolved in water. ${ }^{37}$ Fig. 1a shows the UV-vis spectra of $\mathrm{RhCl}_{3}$ solution in the presence of PVP and in the presence of PVP and ethanol, which are nearly the same. No formation of RhNps was observed in the absence of $\mathrm{NaOH}$. The reddish solutions (inset in Fig. 1a) showed a strong absorption band at around $220 \mathrm{~nm}$ due to the ligand-to-metal charge transfer (LMCT) of the Rh(III) complex $^{38}$ and the contribution of PVP. Two absorption maxima were also observed at 373 and $484 \mathrm{~nm}$ corresponding to the $\mathrm{d}-\mathrm{d}$ electron transition of $\mathrm{Rh}$ (III) ions in the chloroaquorhodium(III) complexes. ${ }^{38}$ Colloidal RhNps were simply synthesized by the direct reduction of $\mathrm{Rh}(\mathrm{III})$ ions by alkaline ethanol solution in the presence of PVP under aerobic conditions at room temperature $\left(20^{\circ} \mathrm{C}\right)$. Fig. $1 \mathrm{~b}$ shows the time evolution of UV-vis spectra of the reaction mixture during the synthesis process. The spectra during the first $10 \mathrm{~min}$ are shown in Fig. 1c to clearly display the absorbance changes at around $645 \mathrm{~nm}$. The absorption maxima for $\mathrm{Rh}$ (III) complex was blueshifted immediately after the addition of ethanol- $\mathrm{NaOH}$ solution which is probably due to the substitution of $\mathrm{Cl}^{-}$by $\mathrm{OH}^{-}$. Two new absorption bands at around 260 and $646 \mathrm{~nm}$ appeared as the color of the mixture changed from reddish to blue. The absorbances at 260 and $646 \mathrm{~nm}$ increased and reached their maximal value $4 \mathrm{~min}$ after the mixture. Then they decreased as the reaction time went on. The reactant turned from blue to pale yellow as the two new absorption bands disappeared 9 min after the mixture, which indicates the appearance and disappearance of transient species.

As the reaction progressed, the whole spectra gradually rised up especially in the visible range, indicating the formation of $\mathrm{Rh}(0)$ particles. After the reduction of $\mathrm{Rh}(\mathrm{III})$ ions was completed (61 min after mixing), there is no remarkable change in the spectrum, as shown in Fig. 1b. The color of the solution turned from pale yellow to dark brown, as the featureless absorption in the visible range increased, indicating that the band structure of Rh particles was formed. ${ }^{38,39}$ Fig. $1 \mathrm{~d}$ shows the photographs of the reactant mixture taken at different stages of the reaction. The color of the reactant mixture clearly changed from reddish to blue, pale yellow and dark brown as described above.
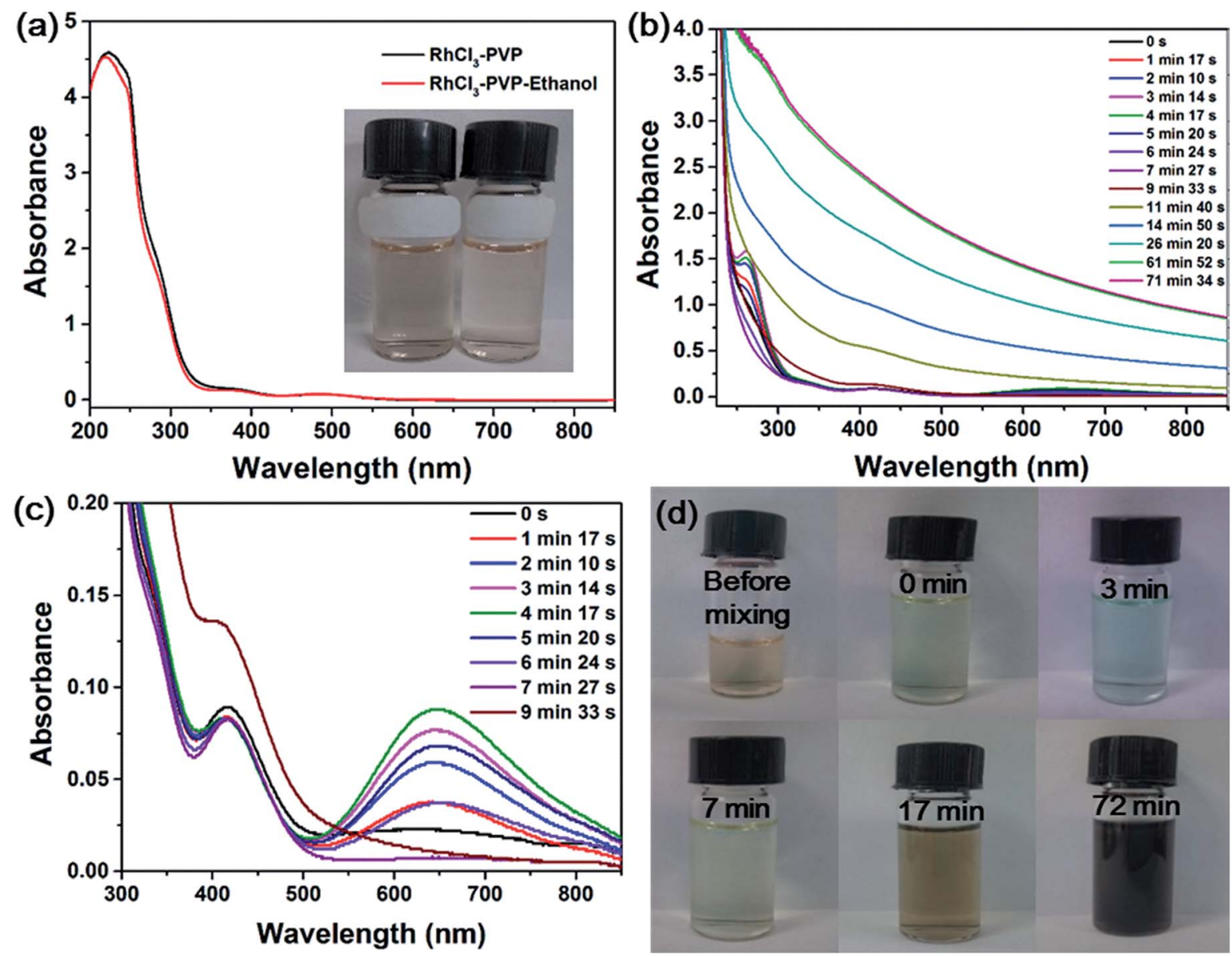

Fig. 1 (a) UV-vis spectra of the solution containing $1 \mathrm{mM} \mathrm{RhCl}_{3}$ and $50 \mathrm{mM} \mathrm{PVP}$ in the absence and presence of $1 \mathrm{M}$ ethanol. The inset shows the color of the solution. Time evolution of the UV-vis spectra of the mixture (b) during the whole process and (c) during the first 10 min. (d) Photographs of the mixture taken at different stages of the reaction: before mixing and $0,3,7,17,72$ min after mixing. Reaction condition of (bd): $1 \mathrm{mM} \mathrm{RhCl}, 50 \mathrm{mM} \mathrm{PVP,}, 1 \mathrm{M}$ ethanol and $1 \mathrm{M} \mathrm{NaOH}$ at $20^{\circ} \mathrm{C}$ in aerobic environment. 
Fig. $2 \mathrm{a}$ and $\mathrm{b}$ show the representative TEM images of RhNps synthesized in $1 \mathrm{M}$ ethanol solution at $20{ }^{\circ} \mathrm{C}$. RhNps tend to aggregate due to the small size and extremely high surface free energy. The morphologies of RhNps are not uniform. The sizes of the nanoparticles were estimated to be $2-5 \mathrm{~nm}$. The HRTEM images of typical single RhNps were shown in Fig. 2c. The lattice fringes of each nanoparticle are along the same direction, suggesting the nature of the as-synthesized RhNps are single crystal. The interplanar crystal spacing was examined to be $0.22 \mathrm{~nm}$, which is very close to the (111) lattice spacing of the face centered cubic (fcc) rhodium, implying that the surface of RhNps were covered by the (111) lattice. The XRD pattern of assynthesized products is shown in Fig. 2d. It exhibits four peaks in the $2 \theta$ range $20-100^{\circ}$ corresponding to diffraction from the (111), (200), (220) and (311) lattice planes and matched with fcc rhodium (JCPDS 88-2334). Therefore the XRD pattern confirmed the formation of fcc RhNps. The average size of RhNps was calculated to be $3.5 \mathrm{~nm}$ using Scherrer equation, which is consistent with TEM images. Fig. 2e shows the Rh $3 \mathrm{~d}$ XPS of RhNps after being deposited on $\mathrm{Al}$ foil. The $\mathrm{Rh} 3 \mathrm{~d}$ region is characterized as a doublet, which arises from the spin-orbit coupling splitting corresponding to $3 \mathrm{~d}_{3 / 2}$ and $3 \mathrm{~d}_{5 / 2}$ electrons respectively. The $R h(0) 3 d_{3 / 2}$ and $R h(0) 3 d_{5 / 2}$ peaks appeared at binding energies of 312.01 and $307.37 \mathrm{eV}$, confirming the formation of RhNps as reported in the literature. ${ }^{\mathbf{4 0 , 4 1}}$ After deconvolution the percentage of the reduced $\mathrm{Rh}(0)$ was estimated to be $68.6 \%$. The XPS spectrum of $\mathrm{O} 1 \mathrm{~s}$ confirmed the
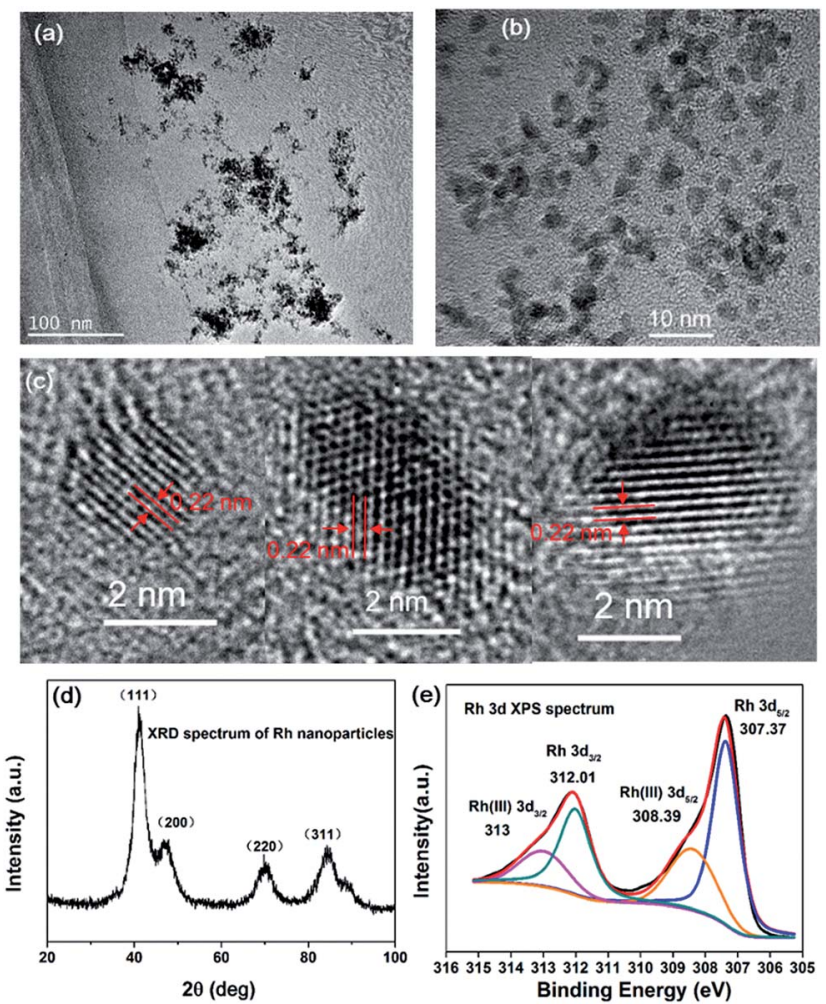

Fig. 2 (a and b) TEM and (c) HRTEM images of the colloidal RhNps. (d) XRD pattern of the RhNps. (e) XPS of the RhNps. Condition of synthesis: $1 \mathrm{mM} \mathrm{RhCl}_{3}, 50 \mathrm{mM}$ PVP, $1 \mathrm{M}$ ethanol and $1 \mathrm{M} \mathrm{NaOH}$ at $20^{\circ} \mathrm{C}$. existence of unreduced Rh(III) (Fig. S1 $\dagger$ ). Two peaks were observed for the $\mathrm{O} 1 \mathrm{~s}$ spectrum of RhNps formed in the absence of PVP at $533.72 \mathrm{eV}$ and $531.31 \mathrm{eV}$, of which the latter corresponded to the oxygen atoms of oxidized Rh(III). EDX was also employed to investigate the valence state of RhNps (Fig. S2 $\dagger$ ). The atomic ratio of $\mathrm{Rh}$ to $\mathrm{O}$ was measured to be $81.7 \%: 18.3 \%$ illustrating the existence of unreduced $\mathrm{Rh}(\mathrm{III})$.

To characterize the origin of the two transient absorption bands observed in Fig. 1, the absorbance variations at 260 and $646 \mathrm{~nm}$ as a function of time were measured, as shown in Fig. 3. The absorbance at $260 \mathrm{~nm}$ reached its maximal after $200 \mathrm{~s}$ reaction and decreased to its minimum after $370 \mathrm{~s}$ reaction, while the absorbance at $646 \mathrm{~nm}$ reached its maximal after $300 \mathrm{~s}$ reaction and decreased to its minimum after $530 \mathrm{~s}$ reaction. It is clear that the variation of the absorbance at $646 \mathrm{~nm}$ falls behind that at $260 \mathrm{~nm}$. Thus we can speculate that the two absorption bands at 260 and $646 \mathrm{~nm}$ are originated from two different transient species.

The spectra properties of $\mathrm{Rh}(\mathrm{II})$ and $\mathrm{Rh}(\mathrm{I})$ complexes, of which the life time varies greatly, have been studied by many literatures. $^{\text {42-47 }}$ Stable $\mathrm{Rh}(\mathrm{II})$ and $\mathrm{Rh}(\mathrm{I})$ complexes, such as $\left(\mathrm{Rh}^{\mathrm{II}}\left(\mathrm{CH}_{3} \mathrm{COO}\right)_{2}\right)_{2}$ and $\left(\mathrm{Rh}^{\mathrm{I}}(\mathrm{CO})_{2} \mathrm{Cl}\right)_{2}$, exist at room temperature. A new absorption peak at $265 \mathrm{~nm}$ was observed by Lilie et al. ${ }^{42}$ in the experiment of pulse radiolytic reduction of $\mathrm{Rh}\left(\mathrm{NH}_{3}\right)_{5} \mathrm{H}_{2} \mathrm{O}^{3+}$ in the presence of isopropanol and oxygen. It was identified as a dioxygen adduct of $\mathrm{Rh}^{\mathrm{II}}\left(\mathrm{NH}_{3}\right)_{4}{ }^{2+}, \mathrm{O}_{2} \mathrm{Rh}^{\mathrm{II}}\left(\mathrm{NH}_{3}\right)_{4} \mathrm{H}_{2} \mathrm{O}^{2+}$, which is stable for several hours. Mulazzani et al. ${ }^{\mathbf{4 3}}$ and Schwarz et al. ${ }^{\mathbf{4 4}}$ both observed a new absorption band at around $260 \mathrm{~nm}$ in a pulse radiolysis study of $\mathrm{Rh}(\mathrm{bpy})_{3}{ }^{3+}$, which was assigned to the generation of $\mathrm{Rh}^{\mathrm{II}}(\mathrm{bpy})_{3}{ }^{2+}$. Generally $\mathrm{Rh}(\mathrm{II})$ complex exhibits strong absorption bands at around $260 \mathrm{~nm}$. As for $\mathrm{Rh}(\mathrm{I})$ complex, at least four forms of $\mathrm{Rh}(\mathrm{I})$ species, with their absorption bands located in the visible region at $485-565 \mathrm{~nm}$, were clearly identified. ${ }^{43}$ The nature of the Rh(I) species, designated as " $\mathrm{Rh}(\mathrm{bpy})_{2}{ }^{+}$", depends upon the $\mathrm{pH}$ of the solution, the concentration of $\mathrm{Rh}(\mathrm{I})$ as well as the nature and concentration of the counter-ion. A short-lived species absorbing at $520 \mathrm{~nm}$ was assigned to a $\mathrm{Rh}(\mathrm{I}) \mathrm{Rh}(\mathrm{II})$ complex by Derai et al. $^{45}$ Some long-

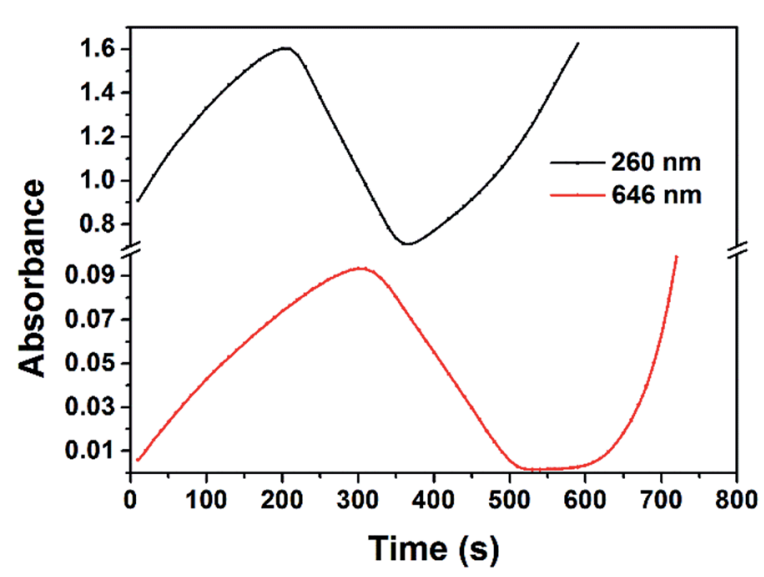

Fig. 3 Absorbance variations at 260 and $646 \mathrm{~nm}$ of the solution containing $1 \mathrm{mM} \mathrm{RhCl}_{3}, 50 \mathrm{mM}$ PVP, $1 \mathrm{M}$ ethanol and $1 \mathrm{M} \mathrm{NaOH}$ at $20^{\circ} \mathrm{C}$ as a function of time. 
lived $\mathrm{Rh}$ (I) $\mathrm{Rh}$ (II) complexes are known to absorb in the $550 \mathrm{~nm}$ region. ${ }^{46,47}$ The transient absorption band at $260 \mathrm{~nm}$ is assigned to intermediate $\mathrm{Rh}$ (II) complex, which corresponds well with other literatures..$^{42-44} \mathrm{Rh}(\mathrm{I})$ complex generally exhibits absorption bands in the visible region, which depends on the ligand that stabilize the complex. ${ }^{43}$ In this work the variation of the absorption band at $646 \mathrm{~nm}$ lags behind that at $260 \mathrm{~nm}$. Thus it is reasonable the broad absorption band at $646 \mathrm{~nm}$ was assigned to $\mathrm{Rh}(\mathrm{I})$ complex.

Oxygen was found to affect the synthesis process markedly. Colloidal RhNps were also obtained when dissolved oxygen was removed from both $\mathrm{RhCl}_{3}-\mathrm{PVP}$ solution and ethanol- $\mathrm{NaOH}$ solution. The time evolution of the UV-vis spectra was monitored during the reaction, as shown in Fig. 4. Compared with the situation in aerobic conditions (Fig. 1b), the whole spectra rised up immediately after the mixing. No transient absorption bands at around 260 and $646 \mathrm{~nm}$ were observed, which means no intermediate $\mathrm{Rh}(\mathrm{II})$ or $\mathrm{Rh}(\mathrm{I})$ complex was observed. $\mathrm{Rh}(0)$ particles were generated more quickly in this situation. It can be concluded oxygen here played a role in stabilizing the $\mathrm{Rh}$ (II) and $\mathrm{Rh}(\mathrm{I})$ complexes, which are easy to be further reduced without enough stabilization of ligands or oxidizing agents. The nature of $\mathrm{Rh}(\mathrm{II})$ and $\mathrm{Rh}$ (I) complexes may be a dioxygen adduct as reported by Lilie et al. ${ }^{42}$

\section{Kinetic study and mechanism of RhNps formation}

The effect of PVP was also investigated. Fig. S3 $\uparrow$ shows the UVvis spectra of $\mathrm{RhCl}_{3}-\mathrm{PVP}$ solution in the presence of different concentrations of $\mathrm{NaOH}$. There is only very slight difference. A weak band at around $415 \mathrm{~nm}$ due to substitution of $\mathrm{Cl}^{-}$by $\mathrm{OH}^{-}$ was observed. It was reported that $\mathrm{Rh}$ (III) is dominated by hydroxylated complexes $\left[\mathrm{Rh}(\mathrm{OH})_{6}\right]^{3-}$ at high $\mathrm{pH}(\mathrm{pH} \geq 12)^{48}$ The yellow solutions (see inset in Fig. S3†), which were stable for at least 24 hours, also indicate the different species of $\mathrm{Rh}$ (III) complex from the reddish neutral $\mathrm{RhCl}_{3}$ solution (see inset in Fig. 1a). No formation of colloidal RhNps was observed in the

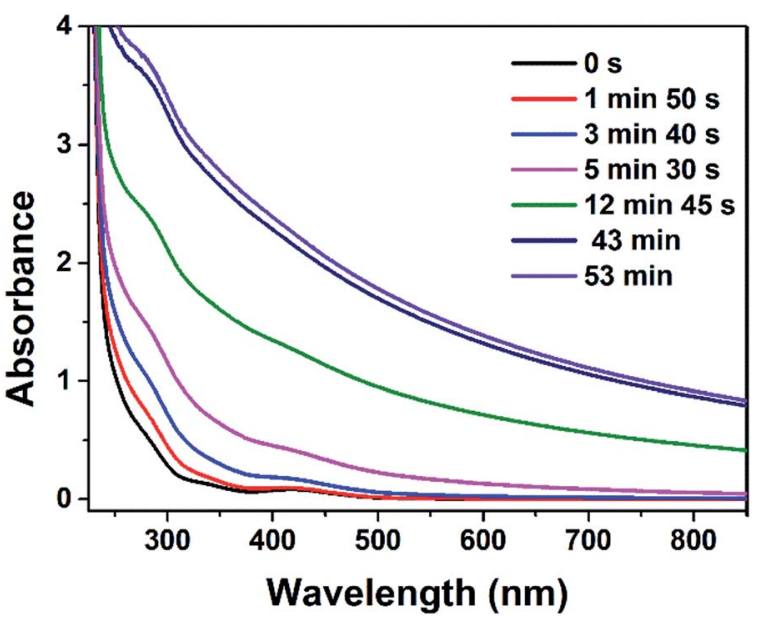

Fig. 4 Time evolution of the UV-vis spectra of the mixture containing $1 \mathrm{mM} \mathrm{RhCl}_{3}, 50 \mathrm{mM} \mathrm{PVP}, 1 \mathrm{M}$ ethanol and $1 \mathrm{M} \mathrm{NaOH}$ at $20^{\circ} \mathrm{C}$ in the absence of $\mathrm{O}_{2}$. presence of PVP and in the absence of ethanol. In our system PVP cannot reduce $\mathrm{Rh}$ (III) ions and only served as a stabilizing agent here.

As discussed above, colloidal RhNps can only be obtained in alkaline medium. The only possible reducing species that are capable of reducing $\mathrm{Rh}$ (III) ions to $\mathrm{Rh}(0)$ at $20^{\circ} \mathrm{C}$ is ethanol in alkaline medium. The effect of $\mathrm{OH}^{-}$concentration on the formation rate of RhNps was studied. Fig. 5a shows the UV-vis spectra of $\mathrm{RhCl}_{3}-\mathrm{PVP}-$ ethanol solution with low concentrations of $\mathrm{NaOH}$. The absorbance increase in the visible range was insignificant unless the concentration of $\mathrm{NaOH}$ reached $0.08 \mathrm{M}$ $(\mathrm{pH}=12.75)$. Therefore to obtain colloidal RhNps the $\mathrm{pH}$ of the solution has to be higher than 12.75 (critical pH).

Alcohol is a kind of weak acid and deprotonates at high pH, as shown in reaction (1):

$$
\mathrm{HR}-\mathrm{OH} \leftrightarrows \mathrm{HR}-\mathrm{O}^{-}+\mathrm{H}^{+}
$$

with the $\mathrm{p} K_{\mathrm{a}}$ of this reaction depending on the nature of $\mathrm{R}$. For example, ethanol, with $\mathrm{p} K_{\mathrm{a}}=15.9\left(25^{\circ} \mathrm{C}\right)$, deprotonates to generate proton and ethoxy anion at high $\mathrm{pH}$, as shown in reaction (2):
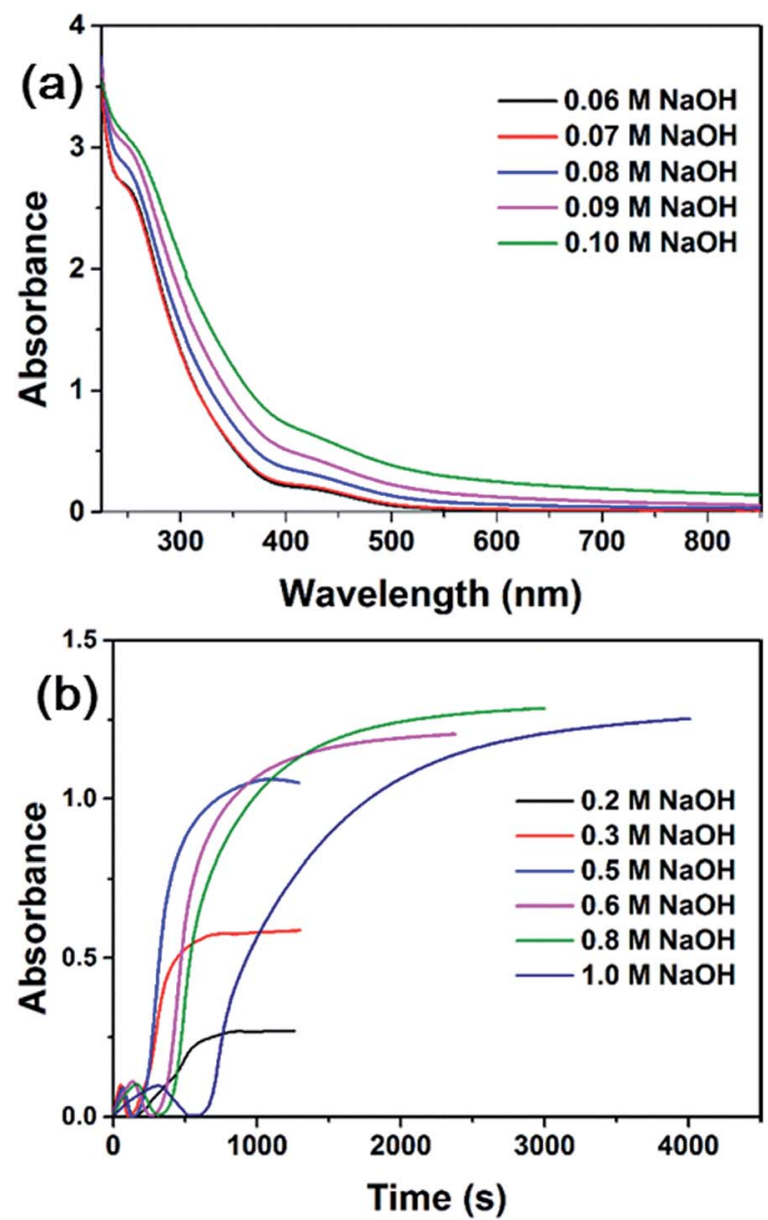

Fig. 5 (a) UV-vis spectra of the solution containing $1 \mathrm{mM} \mathrm{RhCl}_{3}$, $50 \mathrm{mM}$ PVP, $1 \mathrm{M}$ ethanol and $0.06-0.10 \mathrm{M} \mathrm{NaOH}$. (b) Absorbance variations at $646 \mathrm{~nm}$ of the solution containing $1 \mathrm{mM} \mathrm{RhCl}, 50 \mathrm{mM}$ PVP, $1 \mathrm{M}$ ethanol and $0.2-1.0 \mathrm{M} \mathrm{NaOH}$ as a function of time. 


$$
\mathrm{CH}_{3} \mathrm{CH}_{2}-\mathrm{OH} \leftrightarrows \mathrm{CH}_{3} \mathrm{CH}_{2}-\mathrm{O}^{-}+\mathrm{H}^{+}
$$

Kwon et al..$^{49}$ argued that ethoxy anion is the main reactive species at high $\mathrm{pH}(\mathrm{pH} \geq 11)$, with its concentration steeply increasing with higher $\mathrm{pH}$. Ethoxy anion is believed to be significantly more reactive than ethanol, ${ }^{49-51}$ which is much easier for this species to give electrons and be oxidized to acetaldehyde, as shown in reaction (3):

$$
\mathrm{CH}_{3} \mathrm{CH}_{2}-\mathrm{O}^{-} \rightarrow \mathrm{CH}_{3} \mathrm{CHO}+\mathrm{H}^{+}+2 \mathrm{e}^{-}
$$

We propose that ethoxy anion may be responsible for the formation of RhNps in alkaline medium at room temperature. A similar mechanism has been proposed by Gasparotto et al. to explain the formation of AuNps, AgNps and AuAgNps, with glycerol in alkaline medium at room temperature. ${ }^{52-55}$ The alkoxide formed from glycerol in high-pH medium was considered as the true reducing species.

The formation rates of RhNps at $0.2-1.0 \mathrm{M} \mathrm{NaOH}$ were examined by following the absorbance variation at $646 \mathrm{~nm}$ as a function of time (Fig. 5b). The rate of nanoparticle formation and the final absorbance was increased with a higher $\mathrm{NaOH}$ concentration $(0.2-0.5 \mathrm{M})$. The reaction came to an end in $15 \mathrm{~min}$ with $0.5 \mathrm{M} \mathrm{NaOH}$. This can be explained by accounting ethoxy anion as the true reducing species. More ethoxy anion is generated by deprotonation of ethanol with higher concentration of $\mathrm{NaOH}$ (at higher $\mathrm{pH}$ ), thus accelerating the formation of nanoparticles. However, as the concentration of $\mathrm{NaOH}$ further increased (0.6-0.8 M), the formation rate did not increase at all. It even decreased when the concentration of $\mathrm{NaOH}$ reached 1.0 M. With the increase of $\mathrm{NaOH}$ concentration, more $\mathrm{OH}^{-}$can coordinate with $\mathrm{Rh}(\mathrm{III})$ ions and $\mathrm{Rh}(0)$ clusters,${ }^{48}$ thus impede the reduction of unreduced $\mathrm{Rh}$ (III) ions by ethoxy anion. Standard electrode potential of $\mathrm{Rh}$ (III) is closer to zero at $\mathrm{pH}=13.996$ than at $\mathrm{pH}=0,{ }^{56}$ indicating that $\mathrm{Rh}$ (III) is more difficult to be reduced under the stabilization of $\mathrm{OH}^{-}$at high $\mathrm{pH}$. The acceleration effect of $\mathrm{OH}^{-}$on the deprotonation of ethanol plays a dominant role, when the concentration of $\mathrm{NaOH}$ is relatively low, while the impediment effect will be dominant when the concentration of $\mathrm{NaOH}$ is too high. It is noteworthy that the existing time of $\mathrm{Rh}(\mathrm{I})$ complex increased with increasing $\mathrm{NaOH}$ concentration. $\mathrm{OH}^{-}$here also played a role in stabilizing intermediate $\mathrm{Rh}(\mathrm{I})$ complex.

The proposed mechanism was supported by electrochemical tests. The cyclic voltammograms (CV) of GC electrode in neutral and alkaline ethanol solutions are shown in Fig. 6. In neutral medium the oxidation current density was very low indicating that ethanol was difficult to be oxidized on this condition. Ethanol oxidation was slightly enhanced in $0.1 \mathrm{M} \mathrm{NaOH}$ solution. On both conditions the onset potentials were nearly the same at $-0.3 \mathrm{~V}$. In $1.0 \mathrm{M} \mathrm{NaOH}$ solution, the peak current density was much higher with the onset potential shifted $200 \mathrm{mV}$ to more negative potentials, illustrating that ethanol is a stronger reducing agent at higher $\mathrm{pH}$. This is due to the fast increase of ethoxy anions as the $\mathrm{pH}$ of electrolyte increases.

The effect of ethanol concentration on the formation rate of RhNps was also studied. Fig. 7 depicts the absorbance variation

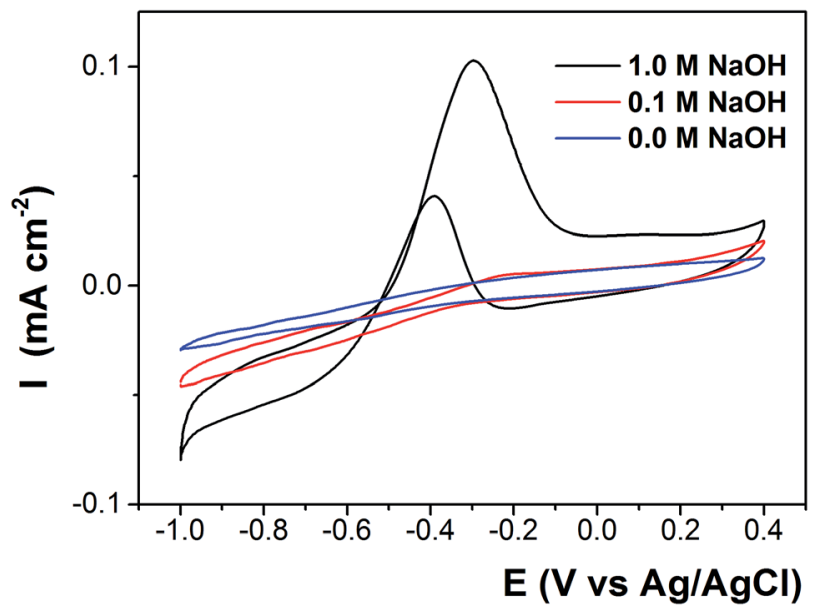

Fig. 6 Cyclic voltammograms (CVs) of GC electrode in $\mathrm{N}_{2}$ saturated solution containing $1.0 \mathrm{M}$ ethanol and $0,0.1,1.0 \mathrm{M} \mathrm{NaOH}$ at $25^{\circ} \mathrm{C}$ with a scan rate of $10 \mathrm{mV} \mathrm{s}^{-1}$.

at $646 \mathrm{~nm}$ as a function of time with the concentration of ethanol varying from 0.1-2.0 M. The rate of RhNps formation was accelerated with increasing ethanol concentration as expected. A higher concentration of ethoxy anion is generated with higher ethanol concentration at the same $\mathrm{pH}$, thus promoting the reduction of $\mathrm{Rh}$ (III) ions and the formation of RhNps. The existing time of $\mathrm{Rh}(\mathrm{I})$ complex decreased with increasing ethanol concentration, because it was further reduced more quickly.

The possibility of preparing RhNps by other alcohols at room temperature in alkaline media was examined. RhNps were also obtained in $1.0 \mathrm{M} \mathrm{NaOH}$ solution in the presence of isopropanol with a much slower kinetics (Fig. 8). It is more difficult for isopropanol to deprotonate into its corresponding alkoxide through reaction (1) because of its higher $\mathrm{p} K_{\mathrm{a}}\left(17.1,25^{\circ} \mathrm{C}\right)$. The critical $\mathrm{pH}$ for isopropanol to produce RhNps at room temperature is 13.05 and higher than that of ethanol (12.75). These results strongly support the mechanism proposed above. Methanol, with a $K_{\mathrm{a}}$ of 15.5 , would be expected to be more

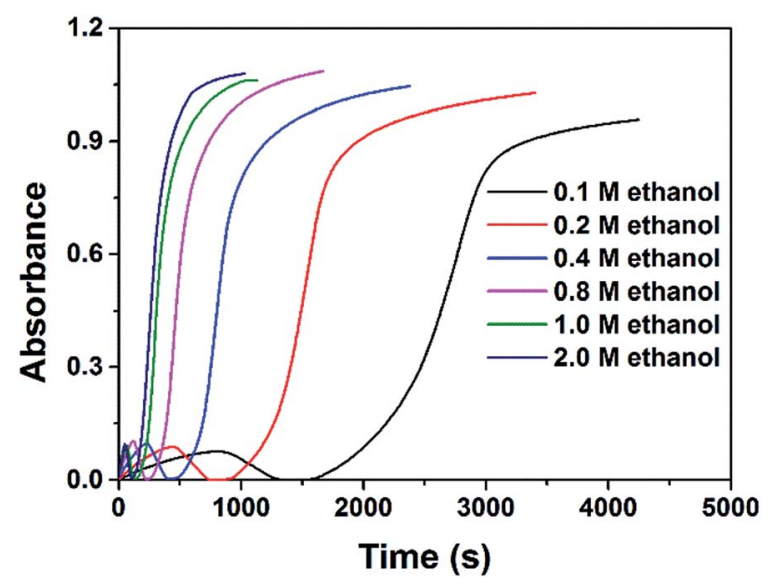

Fig. 7 Absorbance variations at $646 \mathrm{~nm}$ of the solution containing $1 \mathrm{mM} \mathrm{RhCl}_{3}, 50 \mathrm{mM} \mathrm{PVP}, 0.5 \mathrm{M} \mathrm{NaOH}$ and 0.1-2.0 M ethanol as a function of time. 


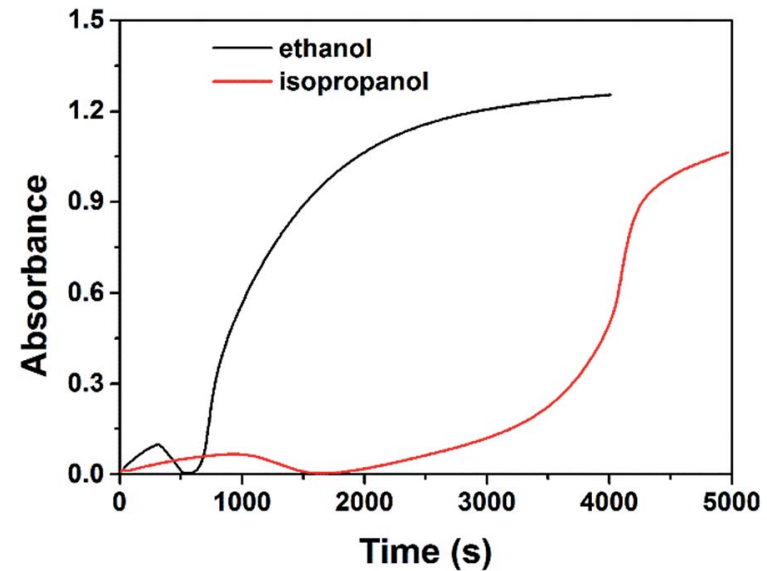

Fig. 8 Absorbance variations at $646 \mathrm{~nm}$ of the solution containing $1 \mathrm{mM} \mathrm{RhCl}, 50 \mathrm{mM} \mathrm{PVP}, 1.0 \mathrm{M} \mathrm{NaOH}$ and $1 \mathrm{M}$ ethanol/isopropanol as a function of time.

reactive than ethanol. However, no RhNps were produced in 1.0 $\mathrm{M} \mathrm{NaOH}$ solution in the presence of methanol in $24 \mathrm{~h}$. This anomaly may be caused by the different leaving ability of the $\alpha$ hydrogen $\left(\mathrm{H}_{\alpha}\right),{ }^{49}$ which means the different ability for alkoxides to give electrons. The bond energy of $\mathrm{C}-\mathrm{H}_{\alpha}$ in methanol is higher than the $\mathrm{C}-\mathrm{H}_{\alpha}$ in ethanol ${ }^{57}$ (no similar data for the corresponding alkoxides has ever been reported as far as we know), meaning that corresponding alkoxide for methanol is less reactive than that for ethanol. Tert-butyl alcohol, with a high $\mathrm{p} K_{\mathrm{a}}$ of 18.0, is expected to be less active than isopropanol. Moreover, there is no $\mathrm{H}_{\alpha}$ for tert-butyl alcohol. No wonder that no RhNps were observed in alkaline tert-butyl alcohol solution at room temperature.

\section{Electrocatalytic performance of $\mathrm{Rh} / \mathrm{C}$ towards ethanol oxidation}

The electrocatalytic activity of commercial and as-synthesized $\mathrm{Rh} / \mathrm{C}$ toward ethanol oxidation in alkaline medium was evaluated, as shown in Fig. 9. The inset in Fig. 9b shows the TEM image of as-synthesized RhNps deposited on Vulcan carbon. The metallic loading was $5.32 \mathrm{wt} \%$ determined by ICP-MS. Fig. 9a shows the $\mathrm{CV}$ curve of $\mathrm{Rh} / \mathrm{C}$ in $\mathrm{N}_{2}$-saturated $0.1 \mathrm{M}$ $\mathrm{NaOH}$ solution. Oxygen adsorption was observed at high potentials in the positive scan, while oxygen desorption occurred at low potentials in the negative scan.

The electrocatalytic performance of commercial and assynthesized $\mathrm{Rh} / \mathrm{C}$ was investigated in a $1 \mathrm{M}$ ethanol $+0.1 \mathrm{M}$ $\mathrm{NaOH}$ solution at $25{ }^{\circ} \mathrm{C}$ (Fig. 9b). In the positive scan, the oxidation of ethanol started from low potentials, and a broad oxidation peak occurred at -0.4 to $0.1 \mathrm{~V}(v s$. $\mathrm{Ag} / \mathrm{AgCl})$ as potential went positively, which is consistent with literatures. ${ }^{26,58}$ After peak potential the current decreased due to the formation of oxidized species blocking the active sites. ${ }^{26}$

In the negative scan, the oxidation current was negligibly low at high potentials. At low potentials an oxidation peak was observed at $-0.63 \mathrm{~V}$ as the oxidized species were removed exposing the active sites. Compared with commercial $\mathrm{Rh} / \mathrm{C}$, the
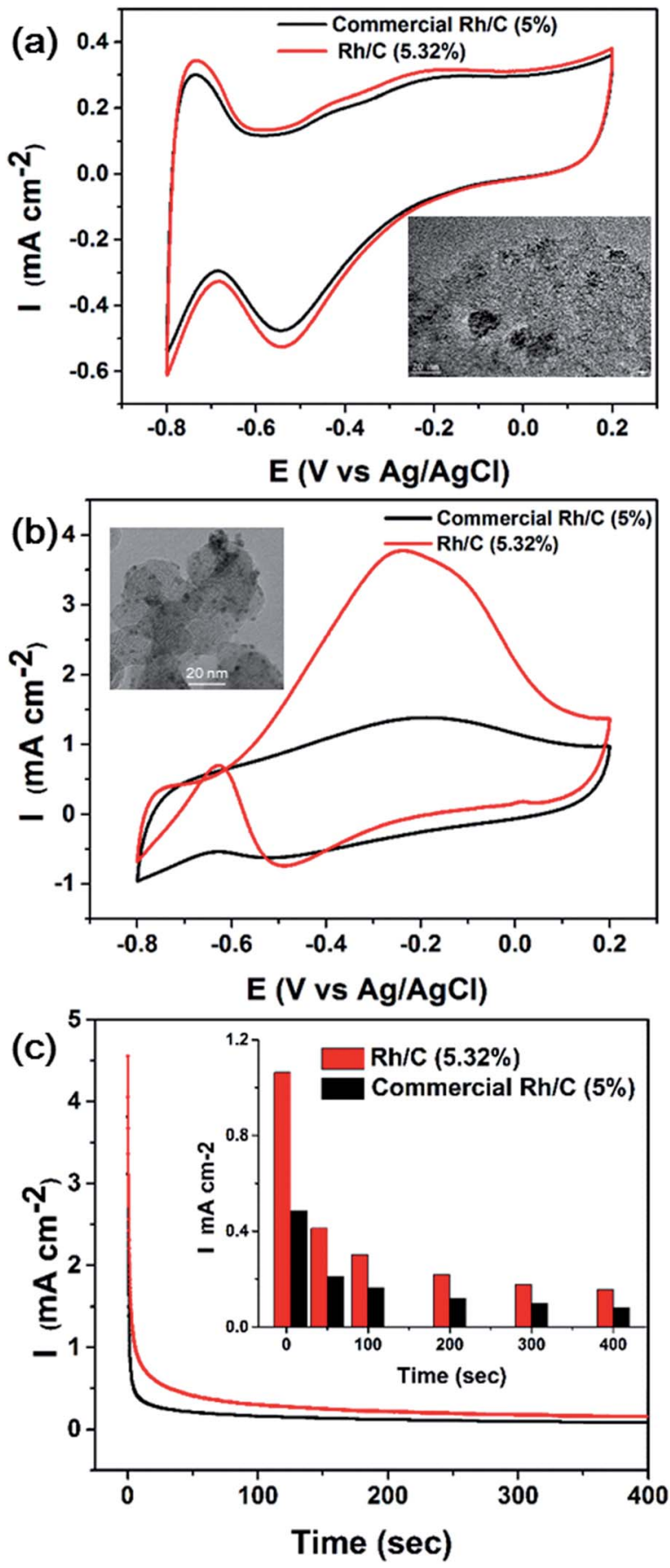

Fig. 9 Cyclic voltammograms (CVs) of commercial and as-synthesized $\mathrm{Rh} / \mathrm{C}$ at $25^{\circ} \mathrm{C}$ with a scan rate of $50 \mathrm{mV} \mathrm{s}^{-1}$ (a) In $0.1 \mathrm{M} \mathrm{NaOH}$ solution. (b) In $1 \mathrm{M}$ ethanol and $0.1 \mathrm{M} \mathrm{NaOH}$ solution. (c) Amperometric l-t curves of as-synthesized and commercial $\mathrm{Rh} / \mathrm{C}$ in $1 \mathrm{M}$ ethanol and $0.1 \mathrm{M} \mathrm{NaOH}$ solution. The inset in (a) shows the TEM image of commercial $\mathrm{Rh} / \mathrm{C}$. The inset in (b) shows as-synthesized $\mathrm{Rh} / \mathrm{C}$.

as-synthesized Rh/C displayed enhanced catalytic activity towards ethanol oxidation. Note that the metallic loadings were nearly the same. And the current density was much higher than commercial $\mathrm{Rh} / \mathrm{C}$ and the onset potential was more negative. The stability tests of the as-synthesized and commercial $\mathrm{Rh} / \mathrm{C}$ were carried out as well. Amperometric $I-t$ curves at $-0.2 \mathrm{~V}$ 
were shown in Fig. 9c. Fig. $\mathrm{S} 4 \dagger$ showed $I-t$ curves at -0.5 and $0 \mathrm{~V}$. Compared with commercial $\mathrm{Rh} / \mathrm{C}$, the as-synthesized $\mathrm{Rh} / \mathrm{C}$ displayed comparable or even better stability. This is due to the difference in dispersity of RhNps on carbon. The nanoparticles of commercial $\mathrm{Rh} / \mathrm{C}$ either were too small or agglomerated into big clusters, as we can see from inset in Fig. 9a.

The electrocatalytic activity of $\mathrm{Rh} / \mathrm{C}$ toward ethanol oxidation in acid medium was also studied, as shown in Fig. S5. $\dagger$ It is obvious that Rh/C showed no activity for ethanol electrooxidation in acid medium. The alkaline environment is key to making $\mathrm{Rh}$ an active catalyst for ethanol oxidation. It is generally acknowledged that the difficulty of $\mathrm{H}_{\alpha}$ dehydrogenation of ethanol in acid medium results in nearly zero activity of Rh due to the lack of hydroxide species, ${ }^{59}$ which is also applicable here. In our opinion, however, the role of ethoxy anions generated from the deprotonation of ethanol by $\mathrm{OH}^{-}$may be overlooked, since they are significantly more reactive than ethanol as has been demonstrated in this work with its concentration steeply increasing with higher $\mathrm{pH}$. This idea helps us fully understand the role of $\mathrm{OH}^{-}$in ethanol oxidation in alkaline medium, which is important for the development of DAEFCs.

\section{Conclusions}

We have for the first time demonstrated a facile and environmentally friendly synthetic route of RhNps through direct reduction of $\mathrm{RhCl}_{3}$ by alkaline ethanol solution in the presence of PVP under aerobic conditions at room temperature. The reaction can be fairly fast. Two transient absorption bands at 260 and $646 \mathrm{~nm}$ were observed in the presence of oxygen and assigned to intermediate $\mathrm{Rh}$ (II) and $\mathrm{Rh}(\mathrm{I})$ complexes respectively, which were stabilized by oxygen and $\mathrm{OH}^{-}$. Ethoxy anions generated from the deprotonation of ethanol at high $\mathrm{pH}$ were responsible for the formation of RhNps. The formation rate of RhNps was increased with higher concentration of ethanol. A proper concentration of $\mathrm{OH}^{-}$would accelerate while too much $\mathrm{OH}^{-}$would impede the formation of RhNps. The low $\mathrm{p} K_{\mathrm{a}}$ and $\mathrm{C}-\mathrm{H}_{\alpha}$ energy of the alcohol was favorable for the formation of RhNps. Moreover, the carbon-supported nanoparticles were highly active and displayed enhanced catalytic activity towards ethanol electrooxidation than commercial $\mathrm{Rh} / \mathrm{C}$ in alkaline medium. The significance of this work is to offer a new facile synthetic route of preparing $\mathrm{Rh}$-based nanocatalysts at room temperature, which may be extended to other nanocatalysts.

\section{Acknowledgements}

We acknowledge financial support for this research from the National Natural Science Foundation of China (No. 21377122 and 31501576), the Fundamental Research Fund for the Central Universities (WK2140000009), and China Postdoctoral Science Foundation (2016M592069).

\section{References}

1 C. Z. Zhu, D. Du, A. Eychmuller and Y. H. Lin, Chem. Rev., 2015, 115, 8896-8943.
2 L. Zhang, Z. X. Xie and J. L. Gong, Chem. Soc. Rev., 2016, 45, 3916-3934.

3 O. S. Wolfbeis, Chem. Soc. Rev., 2015, 44, 4743-4768.

4 M. R. Jones, K. D. Osberg, R. J. Macfarlane, M. R. Langille and C. A. Mirkin, Chem. Rev., 2011, 111, 3736-3827.

5 Y. N. Xia, Y. J. Xiong, B. Lim and S. E. Skrabalak, Angew. Chem., Int. Ed., 2009, 48, 60-103.

6 Z. X. Fan and H. Zhang, Chem. Soc. Rev., 2016, 45, 63-82.

7 L. O. Nindakova, N. M. Badyrova, V. V. Smirnov and S. S. Kolesnikov, J. Mol. Catal. A: Chem., 2016, 420, 149-158.

8 Y. Yuan, N. Yan and P. J. Dyson, ACS Catal., 2012, 2, 10571069.

9 J. R. Renzas, Y. W. Zhang, W. Y. Huang and G. A. Somorjai, Catal. Lett., 2009, 132, 317-322.

10 W. H. Chiou, Y. W. Wang, C. L. Kao, P. C. Chen and C. C. Wu, Organometallics, 2014, 33, 4240-4244.

11 M. H. Tan, G. H. Yang, T. J. Wang, T. Vitidsant, J. Li, Q. H. Wei, P. P. Ai, M. B. Wu, J. T. Zheng and N. Tsubaki, Catal. Sci. Technol., 2016, 6, 1162-1172.

12 E. Antolini and E. R. Gonzalez, J. Power Sources, 2010, 195, 3431-3450.

13 Q. G. He, W. Chen, S. Mukerjee, S. W. Chen and F. Laufek, J. Power Sources, 2009, 187, 298-304.

14 S. Pai-Cheng, C. Hong-Shuo, C. Tsan-Yao, L. Chen-Wei, L. Chih-Hao, L. Jyh-Fu, C. Ting-Shan and W. Kuan-Wen, Int. J. Hydrogen Energy, 2013, 38, 4474-4482.

15 E. H. Yu, U. Krewer and K. Scott, Energies, 2010, 3, 14991528.

16 S. Q. Song, W. J. Zhou, Z. H. Zhou, L. H. Jiang, G. Q. Sun, Q. Xin, V. Leontidis, S. Kontou and P. Tsiakaras, Int. J. Hydrogen Energy, 2005, 30, 995-1001.

17 C. Coutanceau, S. Brimaud, C. Lamy, J. M. Leger, L. Dubau, S. Rousseau and F. Vigier, Electrochim. Acta, 2008, 53, 68656880.

18 A. O. Neto, L. A. Farias, R. R. Dias, M. Brandalise, M. Linardi and E. V. Spinace, Electrochem. Commun., 2008, 10, 13151317.

19 J. P. I. de Souza, S. L. Queiroz, K. Bergamaski, E. R. Gonzalez and F. C. Nart, J. Phys. Chem. B, 2002, 106, 9825-9830.

20 K. Bergamaski, J. F. Gomes, B. E. Goi and F. C. Nart, Ecletica Quim., 2003, 28, 87-92.

21 K. Bergamaski, E. R. Gonzalez and F. C. Nart, Electrochim. Acta, 2008, 53, 4396-4406.

22 F. H. B. Lima, D. Profeti, W. H. Lizcano-Valbuena, E. A. Ticianelli and E. R. Gonzalez, J. Electroanal. Chem., 2008, 617, 121-129.

23 M. Li, W. P. Zhou, N. S. Marinkovic, K. Sasaki and R. R. Adzic, Electrochim. Acta, 2013, 104, 454-461.

24 F. H. B. Lima and E. R. Gonzalez, Electrochim. Acta, 2008, 53, 2963-2971.

25 A. Kowal, M. Li, M. Shao, K. Sasaki, M. B. Vukmirovic, J. Zhang, N. S. Marinkovic, P. Liu, A. I. Frenkel and R. R. Adzic, Nat. Mater., 2009, 8, 325-330.

26 Y. G. Suo and I. M. Hsing, J. Power Sources, 2011, 196, 79457950.

27 E. H. Fontes, R. M. Piasentin, J. M. S. Ayoub, J. C. M. Silva, M. H. M. T. Assumpcao, E. V. Spinace, A. O. Neto and 
R. F. B. Souza, Materials for Renewable and Sustainable Energy, 2015, 4, 1-10.

28 H. Hirai, Y. Nakao and N. Toshima, Journal of Macromolecular Science: Part A-Chemistry, 1978, 12, 1117-1141.

29 J. D. Hoefelmeyer, K. Niesz, G. A. Somorjai and T. D. Tilley, Nano Lett., 2005, 5, 435-438.

30 Y. W. Zhang, M. E. Grass, J. N. Kuhn, F. Tao, S. E. Habas, W. Y. Huang, P. D. Yang and G. A. Somorjai, J. Am. Chem. Soc., 2008, 130, 5868-5869.

31 N. Zettsu, J. M. McLellan, B. Wiley, Y. D. Yin, Z. Y. Li and Y. N. Xia, Angew. Chem., Int. Ed., 2006, 45, 1288-1292.

32 H. Zhang, W. Y. Li, M. S. Jin, J. E. Zeng, T. K. Yu, D. R. Yang and Y. N. Xia, Nano Lett., 2011, 11, 898-903.

33 Z. X. Wu, W. L. Chen, H. Y. Liu, P. Zhai, C. X. Xiao, D. S. Su, H. C. Liu and D. Ma, Catal. Sci. Technol., 2015, 5, 4116-4122.

34 S. Kundu, K. Wang and H. Liang, J. Phys. Chem. C, 2009, 113, 18570-18577.

35 Y. Nakao and K. Kaeriyama, J. Colloid Interface Sci., 1989, 131, 186-191.

36 M. Marin-Almazo, J. A. Ascencio, M. Perez-Alvarez, C. Gutierrez-Wing and M. Jose-Yacaman, Microchem. J., 2005, 81, 133-138.

37 W. C. Wolsey, C. A. Reynolds and J. Kleinberg, Inorg. Chem., 1963, 2, 463-468.

38 M. Harada and Y. Inada, Langmuir, 2009, 25, 6049-6061.

39 M. Harada, N. Tamura and M. Takenaka, J. Phys. Chem. C, 2011, 115, 14081-14092.

40 J. Hedman, R. Nilsson, S. A. Nemnonov, C. Nordling, V. A. Trapezni, M. F. Sorokina, O. I. Kljushni and M. Klasson, Phys. Scr., 1971, 4, 195-201.

41 F. Li, Q. Qian, F. Yan and G. Yuan, Mater. Chem. Phys., 2008, 107, 310-316.

42 J. Lilie, M. G. Simic and J. F. Endicott, Inorg. Chem., 1975, 14, 2129-2133.

43 Q. G. Mulazzani, S. Emmi, M. Z. Hoffman and M. Venturi, J. Am. Chem. Soc., 1981, 103, 3362-3370.
44 H. A. Schwarz and C. Creutz, Inorg. Chem., 1983, 22, 707-713. 45 R. Derai, H. Remita and M. O. Delcourt, Radiat. Phys. Chem., 1991, 38, 483-486.

46 K. R. Mann, N. S. Lewis, V. M. Miskowski, D. K. Erwin, G. S. Hammond and H. B. Gray, J. Am. Chem. Soc., 1977, 99, 5525-5526.

47 I. S. Sigal and H. B. Gray, J. Am. Chem. Soc., 1981, 103, 22202225.

48 A. Cobelo-Garcia, Environ. Sci. Pollut. Res., 2013, 20, 23302339.

49 Y. Kwon, S. C. S. Lai, P. Rodriguez and M. T. M. Koper, J. Am. Chem. Soc., 2011, 133, 6914-6917.

50 J. Szammer, M. Jaky and O. V. Gerasimov, Int. J. Chem. Kinet., 1992, 24, 145-154.

51 V. R. Gangwal, J. van der Schaaf, B. F. M. Kuster and J. C. Schouten, J. Catal., 2005, 229, 389-403.

52 L. H. S. Gasparotto, A. C. Garcia, J. F. Gomes and G. Tremiliosi, J. Power Sources, 2012, 218, 73-78.

53 A. C. Garcia, L. H. S. Gasparotto, J. F. Gomes and G. Tremiliosi, Electrocatalysis, 2012, 3, 147-152.

54 A. G. Garcia, P. P. Lopes, J. F. Gomes, C. Pires, E. B. Ferreira, R. G. M. Lucena, L. H. S. Gasparotto and G. Tremiliosi, New J. Chem., 2014, 38, 2865-2873.

55 J. F. Gomes, A. C. Garcia, E. B. Ferreira, C. Pires, V. L. Oliveira, G. Tremiliosi and L. H. S. Gasparotto, Phys. Chem. Chem. Phys., 2015, 17, 21683-21693.

56 S. G. Bratsch, J. Phys. Chem. Ref. Data, 1989, 18, 1-21.

57 R. Luo, in CRC Handbook of Chemistry and Physics, ed. D. R. Lide, CD-ROM Version, CRC Press/Taylor and Francis, Boca Raton, 90th edn, 2010, pp. 9-71.

58 Q. He, S. Mukerjee, B. Shyam, D. Ramaker, S. ParresEsclapez, M. J. Illan-Gomez and A. Bueno-Lopez, J. Power Sources, 2009, 193, 408-415.

59 G. Cui, S. Song, P. K. Shen, A. Kowal and C. Bianchini, J. Phys. Chem. C, 2009, 113, 15639-15642. 